\title{
IMPORTÂNCIA DO GRUPO PET ENGENHARIA CIVIL DA UFRGS NA FORMAÇÃO PROFISSIONAL E PESSOAL DOS EX-PETIANOS EGRESSOS
}

DOI: 10.37702/2175-957X.COBENGE.2021.3507

Cesar Alberto Ruver - cesar@ufrgs.br

Universidade Federal do Rio Grande do Sul

Rua Coronel Massot 214

91910-530 - Porto Alegre - RS

Camila Cristiane Caumo Zonta - zontacamila@yahoo.com.br Universidade Federal do Rio Grande do Sul

Rua Jacinto Gomes 409

90040-270 - Porto Alegre - RS

Felipe Pereira Vergara - felipepereiravergara@hotmail.com

Universidade Federal do Rio Grande do Sul

Rua Germano Hasslocher 99

90160-050 - Porto Alegre - RS

Katlin Modesto Dorneles - katlinmodestodorneles@gmail.com Universidade Federal do Rio Grande do Sul

Av. Nazário 3780

92035-000 - Canoas - RS

Willian Valli Silva - WillianValli99@gmail.com

Universidade Federal do Rio Grande do Sul UFRGS

Rua Doutor José Ataliba Álvares 105

91751-510 - Porto Alegre - RS

Vítor Schmidt Teixeira - stvitor1@gmail.com

Universidade Federal do Rio Grande do Sul

Rua Doutor Vicente de Paula Dutra 111

90110-200 - Porto Alegre - RS

Nathália Fátima da Silva Dias - nathaliafsdias@gmail.com

Universidade Federal do Rio Grande do Sul

Rua Visconde do Cairu 476 


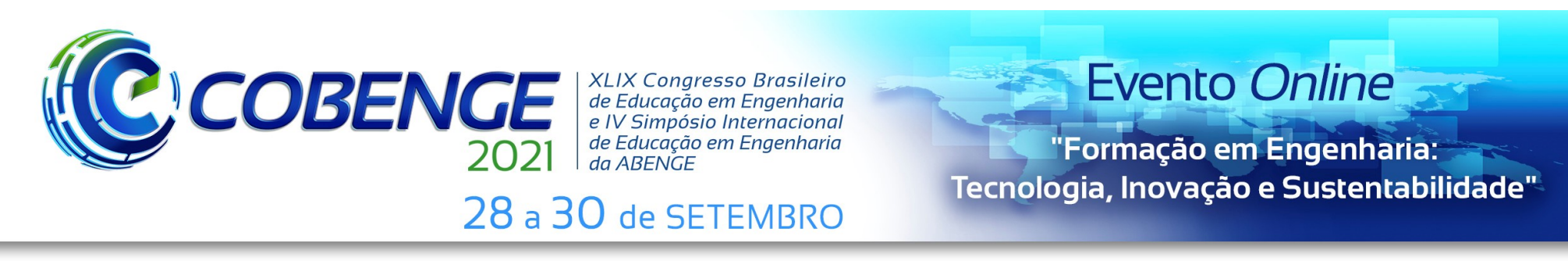

93821-056 - Sapiranga - RS

Gabriel Wesendonck Stalschuss - wesendonck.stalschuss@ufrgs.br

Universidade Federal do Rio Grande do Sul

Rua Barão do Rio Branco 81

98700-000 - ljuí - RS

Júlia Farias - ju.farias.jlf@gmail.com

Universidade Federal do Rio Grande do Sul

Rua Guilheme Gaelzer Neto 51

93819-280 - Sapiranga - RS

Isadora Lemes de Oliveira - isa.lemesdeoliveira@gmail.com

Universidade Federal do Rio Grande do Sul

Rua Francisco Ferrer 355

90420-140 - Porto Alegre - RS

marcelo pasko pereira - marcelopasko@gmail.com

Universidade Federal do Rio Grande do Sul

rua mestre perfeito 220

95670-000 - Gramado - RS

Resumo: Os grupos que compõem o Programa de Educação Tutorial (PET) têm entre suas diversas atribuições, o compromisso de contribuir para elevar a qualidade de ensino dos cursos de graduação, através do desenvolvimento de estratégias e atividades coletivas e interdisciplinares que envolvam tanto os docentes como discentes. Dentre os diversos grupos, pode-se destacar o Grupo PET da Engenharia Civil da UFRGS que teve seu início em 1992, sendo responsável pela formação de excelência de dezenas de engenheiros civis. Assim, considerando que a natureza do PET exige um comprometimento dos petianos (discentes de graduação) com o curso e além da sua própria formação, verifica-se que estes se destacam, não somente durante a vida acadêmica, mas também na carreira profissional, após a conclusão do curso. Neste sentido, o objetivo deste trabalho foi identificar a importância que a participação no Grupo PET Engenharia Civil, desempenhou na formação profissional e pessoal. O trabalho foi desenvolvido através a aplicação de um questionário eletrônico. Para isso foi necessário resgatar o contato (e atualizar) de todos ex-petianos egressos do curso de engenharia civil da UFRGS. Houve retorno de 62 questionários respondidos (51,7\%). De uma forma geral, verificou-se que o PET contribui de forma 


\section{COBENGE

significativa na formação acadêmica, profissional e pessoal, sendo destacado o trabalho em equipe, que foi apontado como um diferencial na carreira dos egressos.

Palavras-chave: Grupo PET Engenharia Civil. Desenvolvimento Profissional e Pessoal. Formação de Excelência. 


\section{IMPORTÂNCIA DO GRUPO PET ENGENHARIA CIVIL DA UFRGS NA FORMAÇÃO PROFISSIONAL E PESSOAL DOS EX-PETIANOS ENGRESSOS}

\section{Introdução}

O PET é um programa tem sua origem em 1979, formatado pela CAPES, sob o nome de "Programa Especial de Treinamento", que foi concebido com o objetivo de contribuir para desenvolvimento do ensino superior. O programa foi gerido durante vinte anos pela CAPES, quando em 1999 passou a fazer parte Secretaria de Educação Superior do Ministério da Educação (SESu/MEC). No ano de 2004, trocou a denominação para "Programa de Educação Tutorial". Em 2005, passou a ser regulado pela Lei Federal no 11.180 de 23 de setembro de 2005 (BRASIL, 2005), além das Portarias do MEC n 3.385 (de 29/09/2005) (MEC, 2005) e 1.632 (de 25/09/2006) (MEC, 2006).

O Programa de Educação Tutorial - PET, atualmente é regido pela Portaria do MEC n 976, de 27 de julho de 2010 (alterado pela Portaria MEC no 343, de 24 de abril de 2013) (MEC, 2010, 2013), que se constitui de (conforme o Art $2^{\circ}$ ):

"... um programa de educação tutorial desenvolvido em grupos organizados a partir de cursos de graduação das instituições de ensino superior do País, orientados pelo princípio da indissociabilidade entre ensino, pesquisa e extensão, que tem por objetivos:

I - desenvolver atividades acadêmicas em padrões de qualidade de excelência, mediante grupos de aprendizagem tutorial de natureza coletiva e interdisciplinar;

II - contribuir para a elevação da qualidade da formação acadêmica dos alunos de graduação;

III - estimular a formação de profissionais e docentes de elevada qualificação técnica, científica, tecnológica e acadêmica;

IV - formular novas estratégias de desenvolvimento e modernização do ensino superior no país;

$V$ - estimular o espírito crítico, bem como a atuação profissional pautada pela cidadania e pela função social da educação superior;

VI - introduzir novas práticas pedagógicas na graduação;

VII - contribuir para a consolidação e difusão da educação tutorial como prática de formação na graduação; e

VIII - contribuir com a política de diversidade na instituição de ensino superior-IES, por meio de ações afirmativas em defesa da equidade socioeconômica, étnico-racial e de gênero....".

$\mathrm{Na}$ formatação atual o Programa de Educação Tutorial é formado por grupos de discentes da graduação, orientador por um professor tutor, que atuam no desenvolvimento de projetos que contemplam a tríade: pesquisa, ensino e extensão, interrelacionado entre si. Tem como objetivo principal a melhoria da graduação, buscando inserir-se no curso ao qual o grupo está vinculado e à Universidade. Neste sentido, o PET visa oferecer aos discentes petianos a realização de atividades extracurriculares para complementação da sua formação acadêmica. Atividades estas, oferecidas para os demais discentes do curso, contribuindo para a melhoria da qualidade do curso como um todo.

Segundo Muller (2003), o PET tem efeitos de curto, médio e longo prazo. Em um primeiro momento, quando o discente ingressa no grupo, sua atuação passa a ser imediata, possibilitando ser agente ativo com envolvimento constante. Os efeitos a médio prazo, 
ocorrem ao longo do tempo, com o maior engajamento dos discentes, sendo que uns ensinam os outros, o que contribui para expansão dos conhecimentos dentro da universidades e para além dela (sociedade). E por fim, a longo prazo, pois o discente que atuou ativamente no grupo, tende a ser um profissional mais consciente, ético e integrado, ou seja, mais preparado para o mercado do trabalho.

Neste sentido, o presente trabalho, pretende focar nos efeitos a longo prazo, na vida dos egressos do Grupo PET Engenharia Civil, de modo a mapear e identificar qual o papel que o Grupo PET teve na contribuição da vida profissional e pessoal. O presente trabalho, se justifica pelo fato da necessidade de mostrar para a comunidade científica e sociedade como um todo, a importância e a necessidade de fomentar a formação extracurricular dos discentes diretamente envolvidos com o PET.

\section{REFERENCIAL TEÓRICO}

Nesta seção são apresentados alguns trabalhos que mostram os resultados e experiências do PET dentro das universidades, principalmente do ponto de vista dos petianos e ex-petianos. Neste sentido, a pesquisa realizada por Damasceno, Brunório e Andrade (2006), com estudantes ingressantes no grupo PET, concluiu que o Programa é de vital importância, pois os petianos tem a oportunidade de ampliar sua vivência acadêmica, contribuindo para um futuro promissor, além disso, traz benefícios para os demais discentes do curso que são beneficiários das atividades promovidas pelos grupos. Neste sentido, os autores apontam que a sociedade também é beneficiada, pois são colocados à disposição profissionais mais qualificados, mais atuantes e comprometidos socialmente. Também concluíram que a atuação no grupo PET Ihes traz mais segurança quanto a sua formação acadêmica e futura expectativa profissional. Segundo Soares et al (2010), o PET visa a formação de profissionais mais capacitados para o mercado de trabalho. Da Silva (2015) cita que a tutoria proporciona ao estudante a autonomia e desenvolve a capacidade de assumir responsabilidades sobre seu próprio aprendizado e desenvolvimento pessoal. Ainda, favorece uma ampliação da visão sobre mundo e a sociedade. Por trata-se de um grupo, a heterogeneidade leva a conflitos, cuja resolução aprimora os valores pessoais e interpessoais.

Balau-Roque (2012), em sua revisão bibliográfica identificou que o envolvimento dos estudantes com o PET pode causar impactos não somente relacionados a formação acadêmica, mas também em relação aos aspectos pessoal, profissional e interpessoal. A autora entende que é importante identificar as razões pela escolha de atuar no PET e as mudanças decorrentes da vivência e participação no grupo PET, durante a graduação. Já segundo Pozza, Ferreira e Domingues (2017), a análise do perfil de egressos é uma ferramenta estratégica que visa avaliar os erros e acertos, em determinados aspectos dentro de um curso, de modo a identificar potencialidades e fragilidades, auxiliando na tomada de decisões na condução e planejamento das instituições de ensino. Conforme Da Silva (2015) a avalição em um sentido mais amplo, não se trata somente como instrumento de controle, mas tem como função julgar os procedimentos e os resultados obtidos, em relação aos esperados. Trata-se de mecanismo de feedback que permite indicar mudanças necessárias nas estratégias e na execução de políticas ou de programas, visando sempre a otimização e melhoria nos resultados.

Dias et al (2009 apud Balau-Roque, 2012) realizou uma pesquisa com egressos de diferentes PET de 57 instituições de ensino superior do país, entre os anos de 1979 (origem) até 2008, com adesão à pesquisa de 2.947 egressos. Verificaram que 93,5\% dos pesquisados atuam na área de formação. Verificaram ainda que $86 \%$ têm título de mestre. Quanto a atuação, 44,91\% atuam na iniciativa privada, 45,21\% atuam no setor público e 0 
restante atua como autônomo ou no setor de prestação de serviços. Outro aspecto abordado pelos autores, foi quanto a formação acadêmica, sendo que $81,5 \%$ dos egressos apontaram que as atividades da tríade (ensino, pesquisa e extensão) teve grande importância na formação e $56,7 \%$ responderam que as atividades do PET contribuíram e aprofundaram os conhecimentos adquiridos nas disciplinas de graduação. $O$ estudo também apontou que a vivência no PET contribuiu para competência técnica, liderança, criatividade, trabalho em equipe e capacidade para lidar com situações complexas.

A pesquisa de Balau-Roque (2012) apontou que de uma amostra de 30 egressos, que atendiam os critérios de "... estar no último ou penúltimo semestre do curso e ter participado do PET por pelo menos dois semestres...", 76,6\% optaram pelo PET como primeira opção como atividade não obrigatória oferecida pelas instituições de ensino superior, sendo apontado entre os principais motivos pela escolha $(68,7 \%)$ : (a) oportunidade de desenvolvimento pessoal e interpessoal, (b) ampliação da formação acadêmica e profissional, (c) atividades desenvolvidas pelos grupos e (extensão), respectivamente. Quanto as mudanças percebidas pelos entrevistados, foi verificado que entre os aspectos positivos apontados destacam-se: (a) habilidades, capacidades e competências acadêmicas; (b) envolvimento acadêmico e (c) aquisição de conhecimentos acadêmicos, respectivamente. Quanto as mudanças positivas acarretadas do ponto de vista profissional, foram destacados: (a) habilidades, capacidades e competências profissionais, (b) composição de rede de contatos profissionais, (c) aquisição de conhecimentos profissionais. Conforme a autora, a experiência no PET apresenta mudanças e impactos positivos, em todas as dimensões pesquisas, quais sejam: (a) acadêmica, (b) profissional, (c) pessoal, e (d) interpessoal.

Da Silva (2015) realizou uma pesquisa junto aos ex-petianos dos cursos de administração, ciências biológicas, economia doméstica e nutrição da Universidade Federal de Viçosa, verificando que somente $57,1 \%$ trabalham, destes $90,6 \%$ atuam na área de formação. Também verificou que $55,5 \%$ levaram menos de seis meses para ingressar no primeiro emprego. Dos egressos que trabalham, $54,1 \%$ atuam na esfera pública. A principal área de atuação é a educacional (52,7\%). Também constatou que 48,8\% consideram-se muito satisfeitos a situação profissional (48,4\%). Do total de pesquisados $79,9 \%$ cursaram pós-graduação. Quanto a atuação no PET, 65\% permaneceram por mais de 25 meses, sendo que 50,5\% consideram a experiência excelente. Dos entrevistados, 67,9\% dominam um idioma estrangeiro. Por fim, 48,1\% consideram que o PET influenciou na sua vida profissional com muita intensidade. A autora constatou que a experiência junto ao PET representou um diferencial na formação dos ex-petianos que participaram da pesquisa.

Soares et al (2010) conduziram uma pesquisa quali-quantitativa com o objetivo de avaliar a percepção dos ex-bolsistas do curso de odontologia da UFBA, com o objetivo de captar sua percepção sobre o programa e analisar na formação acadêmica e inserção no mercado de trabalho. Dos 33 egressos participantes, verificaram que $77,1 \%$ cursaram ou estavam cursando pós-graduação. Do total, $60 \%$ atuam na iniciativa privada e $37,1 \%$ atuam na docência. Um dado importante analisado, diz respeito a influência quanto a escolha profissional, sendo que $94,3 \%$ responderam que foram influenciados pelas atividades desenvolvidas no PET. Segundo os autores, todos os participantes da pesquisa atribuíram fatores positivos quando a sua formação e influência para a inserção no mercado de trabalho, evidenciando a eficácia do programa. Em termos de relevância e atuação das atividades do PET, foram atribuídos os seguintes graus de importância: 87,9\% quanto ao ensino, $85,7 \%$ quanto a pesquisa e $67,6 \%$ quanto a extensão.

Por fim, o trabalho de Ferreira et al (2016) citam que o PET - Medicina veterinária/ Agricultura Familiar UFFS- Campus Realeza, criado em 2010, até o ano de 2015 havia formado 9 profissionais em medicina veterinária. A partir de consulta aos alunos por e-mails 
e a Plataforma Lattes, verificaram que todos atuam na área, sendo que quatro estão realizando residência em Instituições Federais. Com isso, os autores evidenciam que os objetivos do PET estão sendo alcançados.

\section{METODOLOGIA}

O presente estudo baseia-se na metodologia descritiva, do tipo ex-post-facto, com análise quali-quantitativa. Inicialmente, em consulta aos arquivos e documentos digitais e/ou impressos de posse do grupo PET Engenharia civil, realizou-se um levantamento dos ex-petianos bolsistas e não bolsistas que pertenceram ao grupo PET Engenharia Civil da UFRGS, desde sua criação (1992) até o final do ano de 2020. Foi criado um banco de dados inicial, disposto em uma planilha eletrônica contendo o nome; possíveis contatos (email e telefone); data de entrada e saída do grupo, de modo a verificar o tempo de permanência no grupo PET. Ao todo foram identificados 120 ex-petianos formados até o mês de dezembro de 2020.

Posteriormente, foram realizadas buscas on-line em fontes, como: (a) buscadores e ferramentas de pesquisa, tais como Google, Bing, etc.; (b) portais de transparência: federal, estaduais e municipais; (c) mídias sociais: Facebook, Twiter, Instagram, Youtube, Linkedin etc.; (d) Plataformas, como Lattes; (e) Portais de periódicos e bibliotecas; entre outras ferramentas digitais. Estas consultas foram utilizadas para alimentar o banco de dados, contemplando a formação complementar, área de atuação (se dentro da área de formação ou não), posição dentro das organizações nas quais atuam, tempo de atuação, tipo e porte de organização na qual atuam; e demais informações relevantes que pudessem auxiliar na definição do perfil profissional do egresso. Além disso, buscou-se atualizar os contatos, principalmente e-mail, pois muitos endereços eletrônicos estavam desatualizados ou eram institucionais da UFRGS (já inativos). Desta pesquisa, conseguiu-se a atualização de 85 emails válidos e ativos.

Como o objetivo deste trabalho foi mensurar a percepção dos ex-petianos quanto a influência do Grupo PET na formação profissional e pessoal, elaborou-se um questionário eletrônico no GoogleForm, com questões objetivas e descritivos, e opcionais e obrigatórias. O questionário contemplou quatro grupos de questões: (a) dados pessoais (preenchimento do nome opcional), (b) dados acadêmicos, (c) dados profissionais, e (d) percepção sobre o PET. Após a conclusão da elaboração do questionário, o mesmo foi enviado via e-mail para os 85 ex-petianos formados, para que fosse respondido voluntariamente, de caráter individualmente, de forma anônima ou não. Além das questões específicas da pesquisa, solicitou-se dados de contato de outros ex-petianos com os quais ainda mantem contato, com o objetivo de aumentar o banco de dados. Transcorrido o prazo para o preenchimento, filtrou-se os questionários, de modo a verificar a existência de novos contatos. Posteriormente, encaminhou-se novo e-mail para os contatos que não responderam à pesquisa, reiterando o convite para participação, bem como foram incluídos os novos contatos. Além dos e-mails, foi enviado convite para participação, via WhatsApp para os quais não se tinha o endereço de e-mail e que se dispuseram a participar. Com isso, o questionário foi enviado para um total de 96 ex-petianos egressos.

Do total de 96 ex-petianos egressos para os quais se enviou os questionários, houve retorno de $62(64,6 \%)$. Este número corresponde a mais da metade do total de alunos que foram ex-petianos $(51,7 \%)$. Após o recebimento dos questionários, os dados foram tabulados e analisados, dando origem ao presente trabalho. 


\section{$4 \quad$ RESULTADOS}

A pesquisa contou com a participação de 62 ex-petianos egressos do curso de engenharia civil, que abrangeu o período desde a criação do Grupo PET Engenharia Civil, em 1992 até o presente momento. Mais especificamente abrangeu engenheiros civis formados entre o $2^{\circ}$ semestre de 1995 e $2^{\circ}$ semestre de 2019.

Antes de entrar na discussão sobre a relevância do Grupo PET, cabe uma análise do perfil destes ex-petianos. Um primeiro ponto a ser analisado diz respeito ao tempo de permanência no grupo. Neste sentido, pode-se observar pela figura 1 que o maior percentual dos ex-petianos permaneceu entre 3 e 4 semestres $(37,1 \%)$. Também é possível verificar que um pequeno percentual $(11,3 \%)$ permaneceu por um período inferior a dois semestres. Já no outro extremo, verifica-se que que um grande percentual $(27,4 \%)$ permaneceu por um período superior a 7 semestres. Considerando-se o intervalo médio de cada faixa e fazendo-se a média, obtém-se 4,7 semestres de permanência (pouco mais de dois anos e meio). Ainda, em relação ao tempo de permanência, muitos petianos acabam ficando por um período de 2 anos (equivalente a quatro semestres), que é o tempo mínimo exigido pelo Ministério da Educação para emissão do certificado de participação, pela universidade, conforme o modelo da figura 2 (MEC, 2021). Fato confirmado na questão descritiva sobre o motivo da saída do PET, havendo relatos por parte dos ex-petianos que dois anos é um tempo suficiente para desenvolver as habilidades finalistas do programa, bem como um tempo superior, acaba não agregando mais ao grupo.

Figura 1 - Tempo de permanência no Grupo PET Engenharia Civil

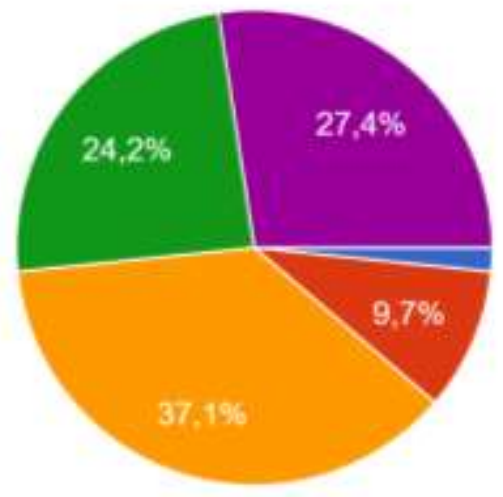

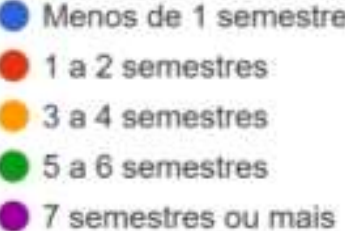

7 semestres ou mais

Figura 2 - Modelo de certificado de participação do PET

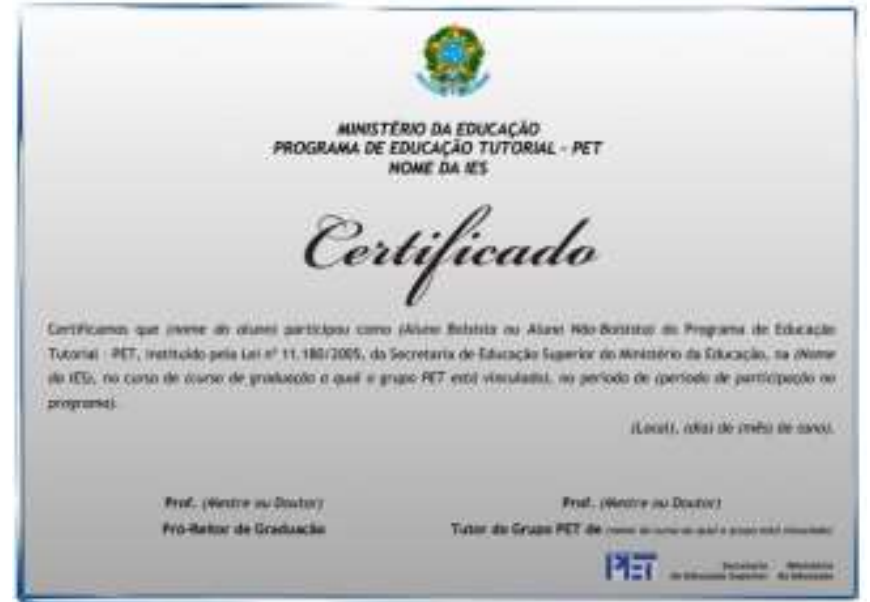

Fonte: MEC (2021) 
A figura 3 diz respeito aos motivos que levaram os ex-petianos a saírem do Grupo PET. Os principais argumento foram a busca de novas oportunidades, sendo elas: (a) estágio (38,3\%), (b) intercâmbio (dupla formação, graduação sanduíche, etc) (20\%), (c) iniciação científica (IC) (10\%), (d) trabalho (3,3\%), e (e) Empresa Júnior (EJECiv) (1,7\%). Os alunos que saíram do PET devido a formatura, constituem um percentual de $11,7 \%$, sendo também alunos que permaneceram por mais de 7 semestres no curso e sendo também os mais antigos integrantes do programa. Como houve um período de mudança de identidade do programa PET, sendo desvinculado da Capes passando a ser assumido pelo Sisu/MEC, conforme mencionado na seção de introdução, também houve um período de corte de recursos e bolsas, motivo que levou alguns alunos a saírem do programa $(8,3 \%)$ de forma prematura, devido a este motivo. Uma das exigências do programa é o critério de bom rendimento acadêmico, que atualmente permite no máximo duas reprovações após o ingresso (MEC, 2010), sendo que houve a saída de 2 ex-petianos (5\%) por esta razão. E por fim, somente um ex-petiano, saiu do programa por alegação de que não se identificou com o programa $(1,7 \%)$.

Figura 3 - Razões para a saída do Grupo PET Engenharia Civil

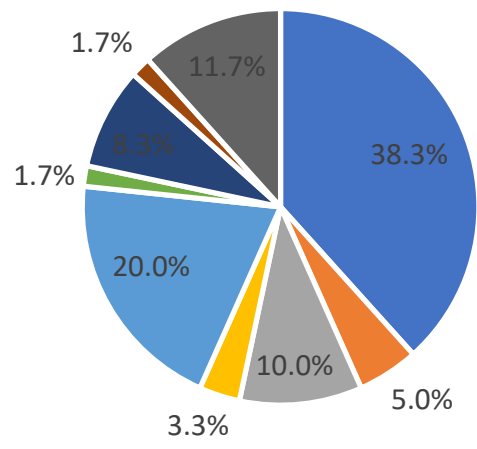

$\begin{array}{ll}\text { - Estágio } & \text { - Reprovação } \\ \text { घ IC } & \text { - Trabalho } \\ \text { - Intercâmbio } \quad \text { - EJECiv } \\ \text { - Corte Bolsa } \quad \text { - Desistência } \\ \text { - Formatura }\end{array}$

A figura 4, mostra o tempo necessário que os ex-petianos egressos do curso de engenharia civil levaram para ingressar no mercado de trabalho. Pelo gráfico é possível verificar que alguns ingressaram diretamente na pós-graduação $(8,3 \%)$ e não diretamente no mercado de trabalho. Se forem somados os percentuais de ex-petianos que ingressaram na pós-graduação, mais os que foram efetivados após a formatura ou que já estavam empregados, e mais os que levaram "menos de 6 meses", verifica-se que 90\%, enquadraram-se no mercado de trabalho com menos 6 meses, após a formatura, mostrando o rápido ingresso e a rápida colocação no mercado de trabalho. Estes dados não levam consideração a atuação na área de formação (engenharia civil) e nem a época em que os ex-petianos se formaram. Isso mostra que mesmo que tenha havido flutuação de demanda de engenheiros no mercado de trabalho e adversidade econômica, os expetianos conseguiram rápida colocação no mercado de trabalho. 
Figura 4 - Tempo necessário para ingressar no mercado de trabalho

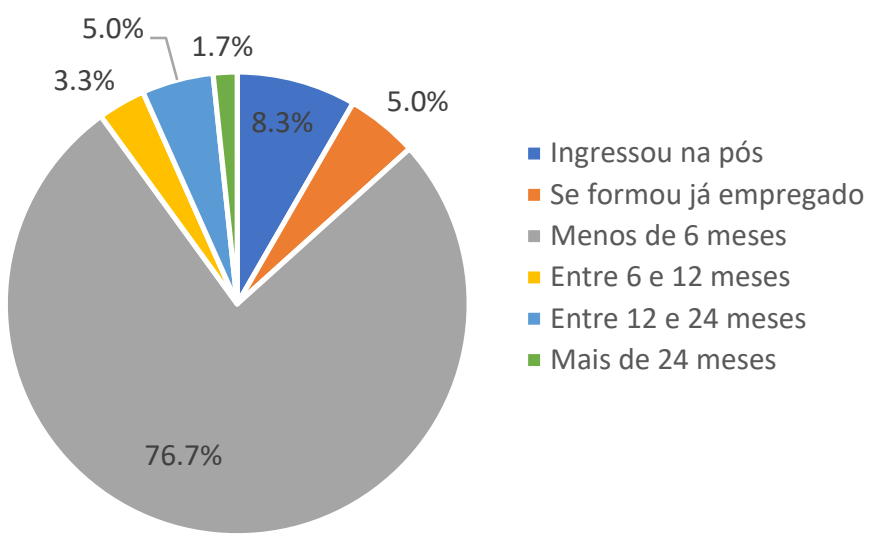

Feita a caracterização e a identificação do perfil dos ex-petianos, foi perguntado sobre a percepção e a contribuição do programa PET na formação profissional e pessoal, do engenheiro civil formado (figuras 5 a 8). Para as questões estabeleceu-se uma graduação (nota) de 1 (não concordo) a 5 (concordo plenamente). De modo a tornar as respostas não tão subjetivos, havia também a opção de resposta descritiva opcional, o que contribuiu para um melhor entendimento e interpretação sobre as questões respondidas. Embora, as questões que envolvam do desenvolvimento das habilidades e capacidades profissionais e humanistas não possam serem desassociados, procurou-se fazer uma análise individualizada de cada item. De uma forma geral, a nota média atribuída na análise geral das respostas de todas as questões foi de 4,54, o que mostra uma contribuição significativamente do programa PET para a formação dos profissionais formados.

A figura 5 aponta a percepção dos ex-petianos quanto a contribuição do PET durante o período de graduação. Neste item, cerca de 3/4 dos ex-petianos concordam plenamente com fato do PET ter sido uma experiência enriquecedora durante o período de graduação. Tomando todos os dados, obteve-se uma nota média de 4,65. Isso está relacionado com o fato de o Grupo PET trabalhar com o desenvolvimento de atividades para aprimoração do curso, atividades de planejamento e de organização. Também, o grupo transita entre as diferentes unidades da Universidade, mantendo contato mais direto com vários professores e profissionais da área. Além disso, agrega-se a isso o fato da permanência e vínculo do discente no grupo, estar vinculada ao bom desempenho acadêmico, conforme Portarias no 976 (MEC, 2010) e no 343 (MEC, 2013), que permite no máximo duas reprovações após o ingresso no PET. 
Figura 5 - "O quanto você concorda que participar do PET foi uma experiência enriquecedora para a sua graduação? (1 - não concordo | 5 - concordo plenamente)"

60

40

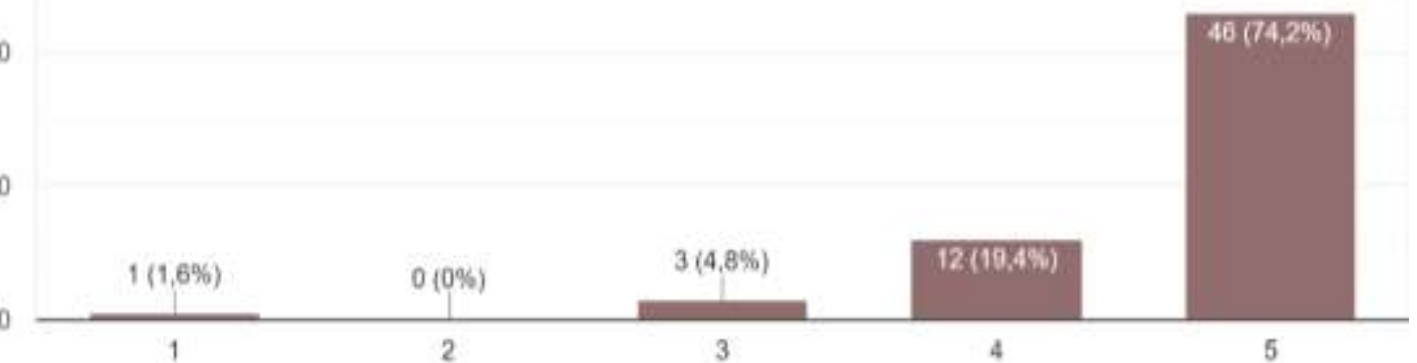

A figura 6 mostra os resultados da questão relacionada a influência na trajetória profissional. Os dados mostram que um pouco mais da metade concorda plenamente que a participação do PET teve uma influência positiva. Na média, obteve-se uma nota 4,40. Isso mostra que o Grupo PET é uma excelente oportunidade de aprimoramento das habilidades profissionais, formando profissionais diferenciados, o que reflete o rápido acesso ao mercado de trabalho, conforme já discutido anteriormente (figura 4). Figura 6 - "O quanto você concorda que participar do PET teve influência positiva na sua trajetória
profissional? $(1$ - não concordo | 5 - concordo plenamente)"

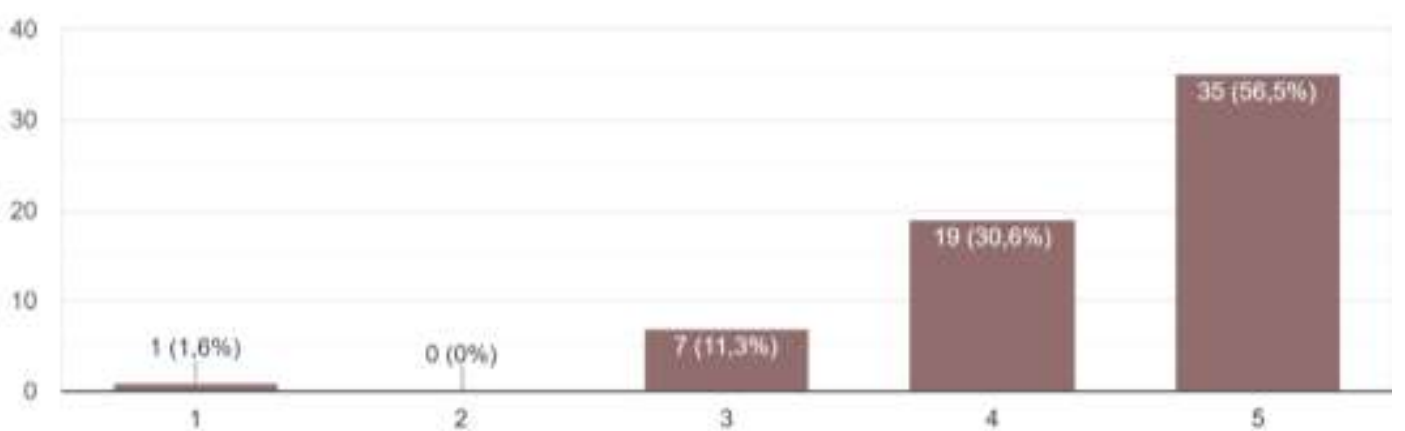

A figura 7, mostra a contribuição do grupo PET na formação humana e altruísta dos ex-petianos. Os dados mostram que cerca de $2 / 3$ concordam plenamente nesta formação, obtendo-se na média uma nota 4,43. Neste aspecto verifica-se que as atividades de extensão, tais como atividades junto as escolas, associações comunitárias, e comunidade em geral, além de auxiliar na solução de problemas sociais e técnicos, desenvolve o lado humanístico dos profissionais formados, tornando os profissionais mais sensíveis as causas sociais, uma vez que o curso é majoritariamente formado por conteúdos técnicos. 
Figura 7 - "O quanto você concorda que as atividades realizadas no PET contribuíram para uma formação humana e altruísta? (1 - não concordo | 5 - concordo plenamente)"

60

40

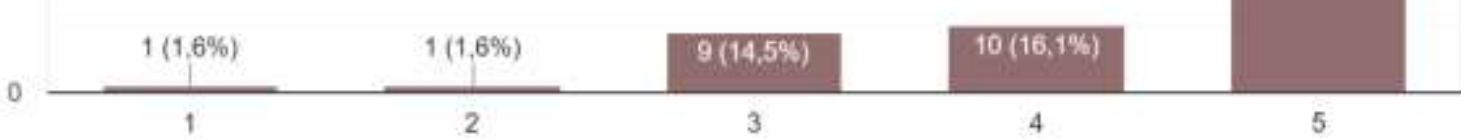

A figura 8 mostra os dados quanto a contribuição na capacidade de trabalho em grupo. Neste item, um pouco mais de 3/4 concordam plenamente no desenvolvimento desta habilidade. Na média, atingiu-se uma pontuação de 4,68. Isso é resultado da organização de trabalho interno do grupo no desenvolvimento e planejamento da execução das atividades desenvolvidas. Também o Grupo PET, desenvolve vários projetos que visam estimular a oratória e apresentação de trabalhos, sendo algumas atividades internas do grupo e outras abertas ao público em geral, a exemplo do projeto "PET Talks" (FONSECA et al, 2020). Vários dos projetos contam com a participação de profissionais da UFRGS que dão feedback sobre a desenvoltura dos participantes. Pode-se verificar que este quesito teve a maior pontuação, sendo de vital importância para a formação profissional.

Figura 8 - "O quanto você concorda que o PET contribuiu para a sua capacidade de trabalhar em equipe? (1 - não concordo | 5 - concordo plenamente)"
60
40

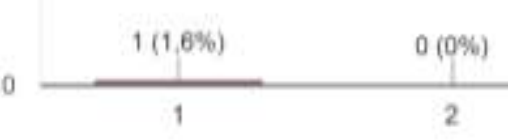
$2(3,2 \%)$
$12(19,4 \%)$
$47(75.8 \%)$
Entre as diversas questões descritivas formuladas, pode-se destacar: "Com o PET você desenvolveu habilidades que posteriormente foram importantes na sua vida pessoal e profissional? Se sim, quais?", todas as respostas foram afirmativas, sendo algumas enfáticas, como "com certeza", (exceto um, que concidentemente, ficou menos de um semestre no grupo e saiu devido ao corte das bolsas). Entre as diversas habilidades apontadas, pode-se destacar: o trabalho em grupo ou equipe, desenvolvimento interpessoal, comunicação e oratória, liderança, gestão de conflitos, entre outras. Como pode ser visto, estas respostas corroboram os demais resultados, principalmente 0 questionamento da figura 8. 


\section{CONSIDERAÇÕES FINAIS}

O resultado deste trabalho de pesquisa, assim, como os demais apontados na capitulo "2 - Referencial Teórico", mais uma vez confirmam a importância das atividades que são desenvolvidas pelo programa PET. Em relação ao Grupo PET Engenharia Civil, verifica-se que o tempo de permanência de 2 anos no programa têm contribuído de forma significativa na formação acadêmica, profissional e humanística. Foi destacado, pelo ex-petianos que as habilidades relacionadas ao trabalho em equipe, sendo um diferencial na carreira profissional. Com isso percebe-se que o programa PET, tem atingido seus objetivos, mostrando ser um programa de excelência e de melhora na qualidade de ensino de graduação.

\section{REFERÊNCIAS}

BALAU-ROQUE, Marina Mercante. Experiência no Programa da Educação Tutorial (PET) e a Formação do Estudante do Ensino Superior. 2012. Dissertação de Mestrado, Programa de Pós-Graduação em Educação. Faculdade de Educação da Universidade Estadual de Campinas (UNICAMP), Campinas, p. 127, 2012.

BRASIL. Lei Federal no 11.180, de 23/09/2005. Brasília, 2005. Disponível em: http://www.planalto.gov.br/ccivil 03/ ato2004-2006/2005/lei/l11180.htm. Acessado em 16/04/2021.

DA SILVA, Maria Luiza Gazolla Reis. Inserção Profissional dos Egressos dos Programas de Educação Tutorial (PET) em Administração, Biologia, Economia Doméstica e Nutrição da UFV. 2015. Dissertação de Mestrado. Programa de PósGraduação em Administração. Universidade Federal de Viçosa (UFV), Viçosa, p. 188, 2015.

DAMASCENO, Renata Fiúza; BRUNÓRIO, Ludimila; ANDRADE, Maria Betânia Tinti de. O Programa de Educação Tutorial - PET - Sob a ótica de bolsistas iniciantes. REME - Revista Mineira de Enfermagem, v10, n2, abr/jun, p. 160-165, 2006.

FERREIRA, Luiz Eduardo; BEDIN, Anderson; DALMUTT, Andressa Carine; BASSANI. Daniella Castro; FOIATO, Diogo Cortese; HERBELE, Elis; FRANKHAUSER, Franciele; GRAVE, Gustavo Luiz; RAMA, Guilherme David; TOFOLLI, Jeferson; BAGATO, Larisa; MOSCON, Rafael; BRUNETTO, Ricael; CHAGAS, Robert Natalino; SKONIESKI, Fernando Reimann; ELIAS, Fabiana. Situação Atual dos Petianos Egressos do PET-Medicina Veterinária/Agricultura Familiar. In: VI Seminário de Educação, Pesquisa e Extensão da Universidade Federal da Fronteira Sul, 2016, Realeza, v. 6, n. 1. Anais. Realeza.

FONSECA, Tainá Garcia da; OLIVEIRA, Isadora Lemes de; RAUBER, Franciele Oliveira; VERGARA, Felipe Pereira; ZONTA, Camila Cristiane Caumo. PET Talks: Ciclo de Seminários Estudantis. In: XXIII-Encontro-Regional-dos-Grupos-PET, 2020, Florianópolis. Anais. Florianópolis.

MINISTÉRIO DA EDUCAÇÃO. Portaria MEC no 1.632, de 25/09/2006. Brasília, 2006. Disponível em: https://www.legisweb.com.br/legislacao/?id=198721. Acessado em 16/04/2021.

MINISTÉRIO DA EDUCAÇÃO. Portaria MEC no 3.385, de 29/09/2005. Brasília, 2005. Disponível em: https://www.legisweb.com.br/legislacao/?id=194240. Acessado em 16/05/2021. 
MINISTÉRIO DA EDUCAÇÃO. Portaria MEC № 343, de 24/04/2013. Brasília, 2010. Disponível em:

http://portal.mec.gov.br/index.php?option=com docman\&view=download\&alias=13005portaria-343-24-abril-2013-pdf\&category slug=abril-2013-pdf\&ltemid=30192. Acessado em 16/04/2021.

MINISTÉRIO DA EDUCAÇÃO. Portaria MEC № 976, de 27/07/2010. Brasília, 2010. Disponível em:

http://portal.mec.gov.br/index.php?option=com docman\&view=download\&alias=14912portaria-n-976\&category slug=dezembro-2013-pdf\&ltemid=30192. Acessado em 16/04/2021.

MINISTÉRIO DE EDUCAÇÃO. Certificados - PET (Modelo). 2021. Disponível em: http://portal.mec.gov.br/pet/arquivos?id=12225. Acessado em 16/04/2021.

MULLER, Angélica. Qualidade no Ensino Superior - a luta em defesa do Programa Especial de Treinamento. Rio de Janeiro: Garamond, 2003.

POZZA, Diovani Luzia; FERREIRA, Rodrigo Campos; DOMINGUES, Maria José Carvalho de Souza. Perfil e Trajetória Profissional dos Egressos de Mestrado em Administração de uma Instituição de Ensino Superior. In: 3o Simpósio de Avaliação do Educação Superior, 2017, Florianópolis. Anais. Florianópolis/SC. pg. 1-11.

SOARES, Felipe Fagundes; DUPLAT, Candice Belchior; FERREIRA, Luiza Palma Luz; RÉGIS, Marcos Ribeiro de Souza; REIS, Silvia Regina de Almeida; MATOS, Mariângela Silva de. Impacto do Programa de Educação Tutorial da Faculdade de Odontologia da Universidade Federal da Bahia na Formação dos Seus Ex-Bolsistas. RPG - Revista de Pós Graduação, 17(3), p. 1432-150, 2010.

\title{
THE SIGNIFICANCE OF THE "PET CIVIL ENGINEERING GROUP" AT UFRGS IN THE PROFESSIONAL AND PERSONAL QUALIFICATION OF "EX-PETIAN" GRADUATES
}

\begin{abstract}
The groups that make up the Tutorial Education Program (PET) have among their various attributions, the commitment to contribute to raise the quality of teaching of undergraduate courses, through the development of collective and interdisciplinary strategies and activities that involve both teachers and students. Among the various groups, we can highlight the PET Civil Engineering Group at UFRGS that started in 1992, being responsible for the excellence training of dozens of civil engineers. Thus, considering that the nature of PET requires a commitment from the petians (undergraduate students) with the course and in addition to their own training, it appears that they stand out, not only during their academic lives, but also in their professional careers, after completion of the course. In this sense, the objective of this work was to identify the importance that the participation in PET Group of Civil Engineering, played in the professional and personal qualification. The work was developed through the application of an online questionnaire. For that, it was necessary to rescue the contact and update all ex-petians who had graduated from the civil engineering at UFRGS. There were 62 questionnaires answered (51.7\%). In general, it was found that PET contributes significantly to academic, professional and personal qualification, with emphasis on teamwork, which was pointed out as a differential in the career.
\end{abstract}

Keywords: PET Civil Engineering Group. Professional and Personal Qualification. Formation of Excellence 